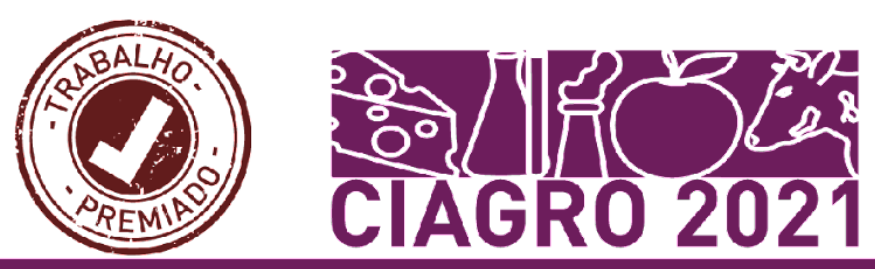

\title{
CAPÍTULO 26: AVALIAÇÃO DO CUSTO DE PRODUÇÃO DE CELULOSE BACTERIANA USANDO SUBPRODUTOS AGROINDUSTRIAIS
}

\section{CAPÍTULO 26: EVALUACIÓN DEL COSTE DE PRODUCCIÓN DE CELULOSA BACTERIANA UTILIZANDO SUBPRODUCTOS AGROINDUSTRIALES}

\section{CHAPTER 26: EVALUATION OF BACTERIAL CELLULOSE COST PRODUCTION USING AGRO-INDUSTRIAL BY-PRODUCTS}

\author{
Pires, M.C. S $^{1}$ Souza, E.F.'; Gottschalk, L.M.F ${ }^{2}$ \\ DOI: https://doi.org/10.31692/978-65-88970-19-5.405-410
}

\section{INTRODUÇÃO}

Os biopolímeros exibem alto potencial de uso em substituição a plásticos e polímeros sintéticos, por serem materiais biodegradáveis e renováveis. Dentre estes, a celulose bacteriana $(\mathrm{CB})$ tem sido usada em aplicações farmacêuticas, biomédicas, membranas condutoras, cosméticos e embalagens comestíveis/inteligentes mas seu potencial pode ser muito maior se a produção ocorrer em larga escala. No entanto, a produção em escala industrial esbarra em limitações como o alto custo dos meios de cultivo e baixo rendimento. A solução para reduzir o custo pode estar no uso de subprodutos da agroindústria como meio de cultivo, por serem boas fontes nutricionais, ao passo que minimizam os impactos ambientais causados pela deposição do subproduto no ambiente. O objetivo do presente trabalho foi comparar o rendimento de produção da CB nos métodos agitado e estático, usando o meio padrão HS e meios alternativos com suco de caju e melaço de soja. Além disso, o custo de produção dos meios utilizados foi avaliado economicamente.

\section{FUNDAMENTAÇÃO TEÓRICA}

$\mathrm{A} C \mathrm{~B}$ se destaca por sua estrutura reticulada ultrafina, alta cristalinidade, resistência à tração, hidrofilicidade e biocompatibilidade (LIN et al., 2013; ROUABHIA et al., 2014).

Vários microrganismos podem produzir celulose bacteriana. Komagataeibacter xylinus se destaca pela capacidade de produzir CB com diferentes fontes de carbono e

\footnotetext{
${ }^{1}$ Graduanda em farmácia, Universidade Estadual da Zona Oeste moniqueserpi@gmail.com

${ }^{2}$ Embrapa Agroindústria de Alimentos, erika.fraga@embrapa.br

Embrapa Agroindústria de Alimentos, leda.fortes@embrapa.br
} 


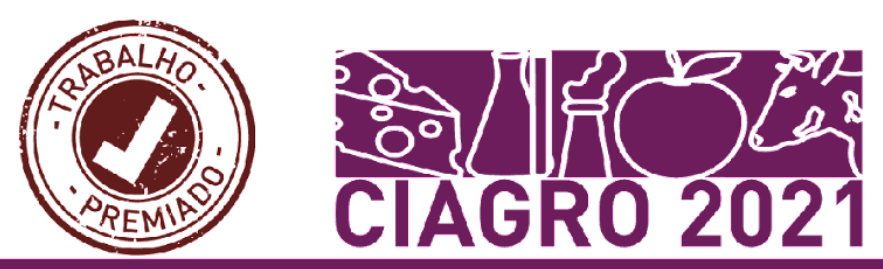

nitrogênio (HUANG et al, 2014). O método de produção pode ser estático, bem elucidado, entretanto, inviável para escala industrial devido longo tempo de biossíntese ou agitado, que exibe alto rendimento e grande potencial para uso em escala comercial, mas o produto formado tem qualidade inferior e pode levar a formação de células mutantes negativas que crescem, turvam o meio e não produzem celulose (RECOUVREUX et al., 2011; WANG et al., 2016).

O Brasil é o segundo maior produtor de soja do Brasil e o nordeste brasileiro é um grande produtor de caju, cujo produto de maior importância é a castanha (FONTES et al., 2013, EMBRAPA, 2019). O suco de caju (SC) é rico em carboidratos e pobre em nitrogênio, necessitando de suplementação, que pode ser feita com o melaço de soja, rica fonte desse nutriente. Estudos realizados por Duarte et al., (2015), Pinheiro (2016) e Souza et al., (2020) têm mostrado o uso desses subprodutos na produção de celulose bacteriana.

\section{METODOLOGIA}

\section{Substratos}

Os reagentes utilizados na elaboração dos meios foram adquiridos na empresa Merck ${ }^{\circledR}$. O suco de caju foi coletado em Pacajus (Ceará, Brasil), o melaço de soja foi gentilmente doado pela Selecta ${ }^{\circledR}$ soybean(Araguarí, Minas Gerais, Brasil), armazenados em recipientes a $4^{\circ} \mathrm{C}$ até a sua utilização.

\section{Caracterização de substratos}

O teor de proteínas foi determinado pelo método de Lowry (LOWRY et al., 1951), os lipídios foram determinados com extração com éter usando um sistema automático (Ankom XT15, EUA). Os açúcares redutores totais (glicose e frutose) foram determinados pelo método DNS (MILLER, 1959). Os resultados serão apresentados com a média da triplicata.

\section{Microrganismo e meios de cultura}

A cepa K. xylinus ATCC 53582 foi utilizada para produção de CB. Para o pré-inóculo, a bactéria foi inoculada em tubos contendo $5 \mathrm{~mL}$ de meio padrão $\mathrm{HS}$. Os tubos foram 


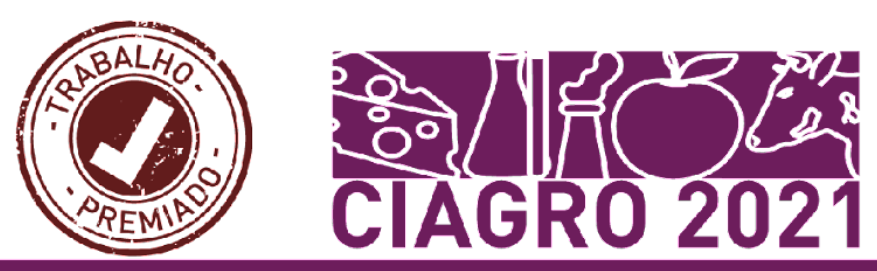

incubados a $30{ }^{\circ} \mathrm{C}$ por $48 \mathrm{~h}$. Após este período, os pré-inóculos foram misturadas e usadas para inocular o meio.

\section{Meios de cultura}

Meio HS: O meio padrão usado neste estudo foi composto por $\left(\mathrm{g} \mathrm{L}^{-1}\right)$ : glicose - 20; peptona - 5; extrato de levedura - 5; fosfato dissódico (anidro) - 2,7; ácido cítrico (monohidrato) - 1,15.

Meio suco de caju com extrato de levedura: O SC foi filtrado através de um filtro de papel qualitativo (Unifil, Alemanha) para separar o material sólido em suspensão. Os açúcares redutores foram determinados pelo método DNS e o suco foi diluído com água destilada até a concentração final de açúcares redutores de $20 \mathrm{~g} \mathrm{~L}-1$. Separadamente uma solução de extrato de levedura $\left(10 \mathrm{~g} \mathrm{~L}^{-1}\right)$ foi preparada e adicionada ao meio.

Meio suco de caju com melaço de soja: O SC filtrado foi diluído com água destilada para $20 \mathrm{~g} \mathrm{~L}^{-1}$ de açúcares redutores. O melaço de soja diluído a $12 \mathrm{~g} \mathrm{~L}^{-1}$ foi adicionado como fonte de nitrogênio.

Nos meios usados no cultivo agitado foram adicionados de $1,5 \%$ de carboximetilcelulose.

\section{Condições de produção CB}

Após o preparo, em triplicata, os meios preparados foram distribuídos, $50 \mathrm{~mL}$ de cada meio em Erlenmeyer de $250 \mathrm{~mL}$ e autoclavado a $121^{\circ} \mathrm{C}$ por 15 . O inóculo foi realizado de acordo com a D.O. obtida. Os cultivos foram realizados a $30^{\circ} \mathrm{C}$ durante 3 dias em condições estáticas e agitadas em Shaker 150 rpm para comparação.

\section{Recuperação e purificação da celulose bacteriana}

Após a fermentação, o meio foi centrifugado (Thermo Fisher Sci-entific, Waltham, MA, EUA) a $4000 \mathrm{rpm}$ por $15 \mathrm{~min}$. As membranas e géis de CB foram colhidos e purificadas por tratamento com $\mathrm{NaOH} 1 \mathrm{M}$ a $80^{\circ} \mathrm{C}$ durante $1 \mathrm{~h}$ (A CB produzida em meio alternativo passou por uma etapa prévia com SDS). Por fim, a CB foi lavada com água destilada até pH 7,0 e submetida a secagem em estufa por $24 \mathrm{~h}$ a $60^{\circ} \mathrm{C}$.

\section{RESULTADOS E DISCUSSÃO}




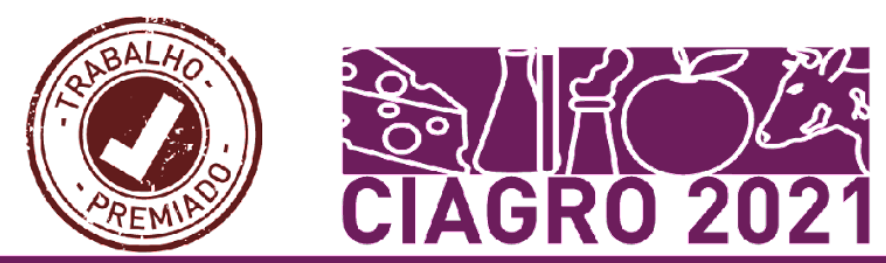

\section{Caracterização do substrato}

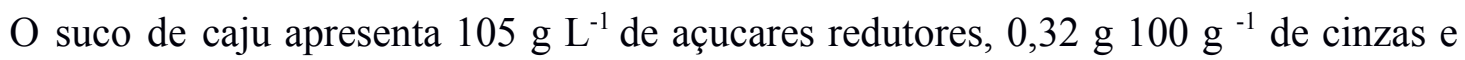
Finare $0,05 \mathrm{~g} 100 \mathrm{~g}^{-1}$ de nitrogênio total. O melaço contém $153 \mathrm{~g} \mathrm{~L}^{-1}$ de açúcares redutores, $67 \mathrm{~g} \mathrm{~L}^{-1}$

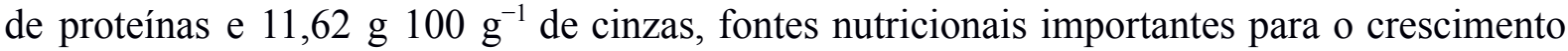
bacteriano (SIQUEIRA et al., 2008). Considerando que o suco de caju apesar de ser rico em açucares, é pobre em nitrogênio, o extrato de levedura e melaço de soja foram avaliados como fonte de nitrogênio.

\section{Produção de celulose bacteriana}

Devido a tendência de formação de células mutantes negativas em cultivo agitados, estudos sugerem o uso de aditivos que inibam esse processo, como os polímeros, capazes de reduzir a mutação por interferir na viscosidade do meio. Nesse estudo foi utilizada a carboximetilcelulose por demonstrar considerável aumento na produção de $\mathrm{CB}$, além de favorecer a formação de pellets (CHENG et al., 2009). Os resultados obtidos no cultivo estático foram $2,02 \mathrm{~g} / \mathrm{L}, 2,27 \mathrm{~g} / \mathrm{L}$ e $2,25 \mathrm{~g} / \mathrm{L}$ respectivamente para o meio padrão $\mathrm{HS}$ e alternativos caju com extrato e caju com melaço. Os resultados obtidos no cultivo agitado foram 2,86 g/L, 2,91 g/L e 2,66 g/L respectivamente para o meio padrão $\mathrm{HS}$ e alternativos caju com extrato e caju com melaço.

Figura 01: Rendimento de celulose bacteriana em cultivo estático e agitado com meio padrão e meios alternativos após 3 dias

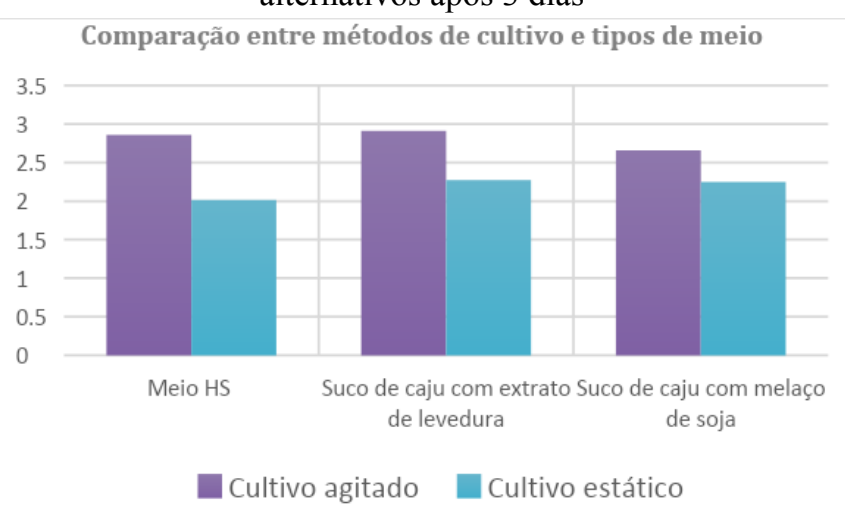

Fonte: Própria (2021)

A adição de $\mathrm{CMC}$ ao cultivo agitado levou ao aumento do rendimento de $\mathrm{CB}$, em comparação ao cultivo estático para todos os meios testados, conforme pode ser observado na Figura 1, viabilizando dessa forma o cultivo agitado em detrimento ao estático. Dentre os 


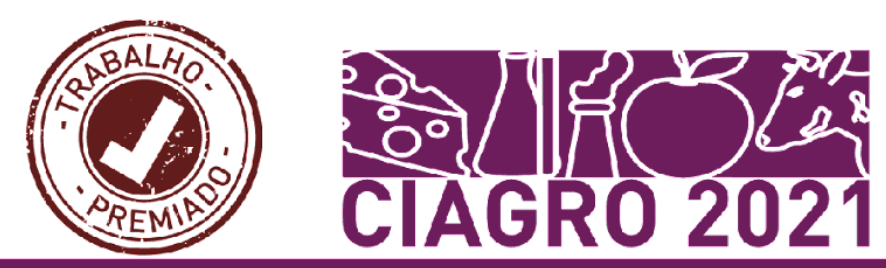

meios alternativos analisados, o cultivo agitado no meio suco de caju com extrato de levedura levou ao maior rendimento $(2,91 \mathrm{~g} / \mathrm{L})$. Ainda assim, o meio suco de caju com melaço de soja também se mostrou com rendimento satisfatório nas condições testadas.

\section{Custo dos meios de cultivo}

Ao longo dos anos, diferentes subprodutos agroindustriais foram avaliados para a produção de CB (Fan et al., 2016; Güzel e Akipinar 2019) e a associação entre melaço de soja e suco de caju (Souza et al., 2019) apresentou resultado superior aos demais. Como pode ser observado no Quadro 01 o uso de subprodutos agroindustriais suco de caju e melaço de soja possibilitou a redução dos custos do meio de cultivo. O meio suco de caju com extrato de levedura reduziu em $40 \%$, enquanto o meio suco de caju com melaço de soja reduziu em $70 \%$ em comparação com o custo estimado para a produção em meio HS.

Quadro 01: Custo do meio de cultivo padrão e alternativo sob agitação.

\begin{tabular}{|c|c|c|c|c|c|}
\hline \multicolumn{2}{|l|}{ Meio HS } & \multicolumn{2}{|c|}{$\mathrm{R} \$ \mathrm{Kg}-1$ reagente } & g L-1 & Custo médio \\
\hline \multicolumn{2}{|l|}{ Glicose } & \multicolumn{2}{|c|}{456} & 20 & 9,12 \\
\hline \multicolumn{2}{|l|}{ Extrato de levedura } & \multicolumn{2}{|c|}{933} & 5 & 4,66 \\
\hline \multicolumn{2}{|l|}{ Peptona } & \multicolumn{2}{|c|}{1760} & 5 & 8,80 \\
\hline \multicolumn{2}{|l|}{ Ácido Cítrico } & \multicolumn{2}{|c|}{560} & 1,5 & 0,84 \\
\hline \multicolumn{2}{|l|}{ Fosfato dissódico (anidro) } & \multicolumn{2}{|c|}{738} & 2,7 & 1,99 \\
\hline \multicolumn{2}{|l|}{ Carboximetilcelulose } & \multicolumn{2}{|c|}{912} & 10 & 9,12 \\
\hline \multicolumn{5}{|c|}{ Meio HS R\$ L-1 } & 34,54 \\
\hline $\begin{array}{c}\text { Meio suco de caju com extrato de } \\
\text { levedura }\end{array}$ & \multicolumn{2}{|c|}{$R \$ L-1$ reagente } & mL L-1 & g L-1 & Custo médio \\
\hline Suco de caju & \multicolumn{2}{|c|}{4,4} & 200 & AT & 0,88 \\
\hline Extrato de levedura & \multicolumn{2}{|c|}{933} & - & 12 & 11,20 \\
\hline Carboximetilcelulose & \multicolumn{2}{|c|}{912} & - & 10 & 9,12 \\
\hline \multicolumn{5}{|c|}{$\begin{array}{l}\text { Meio suco de caju com extrato de levedura R\$ L-1 } \\
\end{array}$} & 21,20 \\
\hline $\begin{array}{c}\text { Meio suco de caju com melaço de } \\
\text { soja }\end{array}$ & $\begin{array}{c}\text { RS L-1 } \\
\text { reagen } \\
\text { te } \\
\end{array}$ & mL L-1 & g L-1 & $\begin{array}{l}\text { Custo } \\
\text { médio }\end{array}$ & \\
\hline Suco de caju & 4,4 & 200 & $\mathrm{AT}$ & 0,88 & \\
\hline Melaço de soja & 0,3 & 150 & AT & 0,04 & \\
\hline Carboximetilcelulose & 912 & - & 10 & 9,12 & \\
\hline \multicolumn{4}{|c|}{ Meio suco de caju com melaço de soja R\$ L-1 } & 10,05 & \\
\hline
\end{tabular}

\section{CONCLUSÃO}

Foi possível produzir a celulose bacteriana usando meios alternativos tanto no método agitado quanto no estático. Em todos os meios avaliados, a produção no cultivo agitado adicionado de carboximetilcelulose $1 \%$ foi maior do que no cultivo estático. A maior 


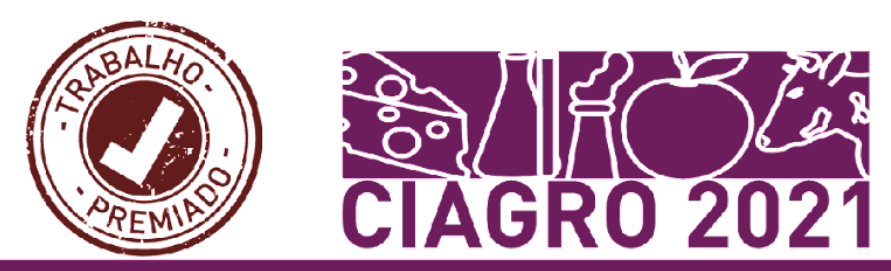

produção de celulose $(2,91 \mathrm{~g} / \mathrm{L})$ foi obtida em suco de caju com extrato de levedura, sendo esse rendimento próximo ao obtido com o meio padrão HS e com custo $40 \%$ inferior.

\section{REFERENCIAS}

CHENG, Kuan-Chen; CATCHMARK, Jeffrey M.; DEMIRCI, Ali. Effect of different additives on bacterial cellulose production by Acetobacter xylinum and analysis of material property. Cellulose, v. 16, n. 6, p. 1033-1045, 2009.

DUARTE, Eden B. et al. Utilização de resíduos agroindustriais na elaboração de bionanocompósitos baseados em celulose bacteriana e Hidroxiapatita. In: Embrapa Agroindústria de Alimentos-Artigo em anais de congresso (ALICE). In: CONGRESSO BRASILEIRO DE POLÍMEROS, 13., 2015, Natal. São Carlos: Associação Brasileira de Polímeros], 2015., 2015.

FAN, Xin et al. Production of nano bacterial cellulose from beverage industrial waste of citrus peel and pomace using Komagataeibacter xylinus. Carbohydrate polymers, v. 151, p. 1068-1072, 2016.

GUBA, E. G.; LINCOLN, Y. S. Fourth generation evaluation. Newbury Park, London, New Delhi: Sage, 1989.

GÜZEL, Melih; AKPINAR, Özlem. Production and characterization of bacterial cellulose from citrus peels. Waste and biomass valorization, v. 10, n. 8, p. 2165-2175, 2019.

HUANG, Yang et al. Recent advances in bacterial cellulose. Cellulose, v. 21, n. 1, p. 1-30, 2014.

LIN, Shin-Ping et al. Biosynthesis, production and applications of bacterial cellulose. Cellulose, v. 20, n. 5, p. 2191-2219, 2013.

LOWRY, Oliver H. et al. Protein measurement with the Folin phenol reagent. Journal of biological chemistry, v. 193, p. 265-275, 1951.

MILLER, Gail Lorenz. Use of dinitrosalicylic acid reagent for determination of reducing sugar. Analytical chemistry, v. 31, n. 3, p. 426-428, 1959.

PINHEIRO, JOSÉ AURÉLIO. Aspectos técnicos e avaliação de ciclo de vida da extração de nanocristais de celulose bacteriana produzida em suco de caju. Embrapa Agroindústria Tropical-Tese/dissertação. 2016.

RECOUVREUX, D., RAMBO, C., BERTI, F., CARMINATTI, C., ANTÔNIO, R., PORTO, L. Novel threedimensional cocoon-like hydrogels for soft tissue regeneration. Mater. Sci. Eng., v. 31, p. 151- 157, 2011. 


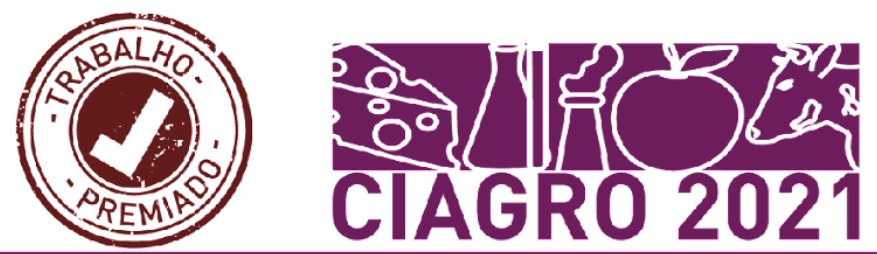

ROUABHIA, Mahmoud et al. Production of biocompatible and antimicrobial bacterial cellulose polymers functionalized by RGDC grafting groups and gentamicin. ACS Applied PIn: Materials \& Interfaces, v. 6, n. 3, p. 1439-1446, 2014.

SIQUEIRA, Paula F. et al. Produção de bioetanol a partir de melaço de soja por Saccharomyces cerevisiae em escala de laboratório, piloto e industrial. Tecnologia Bioresource, v. 99, n. 17, pág. 8156-8163, 2008.

SOUZA, Erika F. et al. Production and characterization of Gluconacetobacter xylinus bacterial cellulose using cashew apple juice and soybean molasses. International journal of biological macromolecules, v. 146, p. 285-289, 2020.

WANG, Z.-G. et al. Preparation of an inoculum of Gluconacetobacter xylinus without mutants in shaken culture. Journal of applied microbiology, v. 121, n. 3, p. 713-720, 2016. 